\title{
INTUITIONS OF ADULT L2-LEARNER AND TRANSLATION STUDENTS AS A GUIDE TO ANALYSIS IN TEACHING*
}

\author{
K. CONNORS
}

Université de Montréal

\begin{abstract}
This paper deals with the pedagogical implications of a series of studies on linguistic awareness. Adult learners, native-, and near-native speakers of English were studied for their knowledge of equivalence and contrast relations between reflexive and emphatic -self constructions, on the one hand, and the possible interpretations of French pronominal-verbal constructions, on the other. In the pilot study, adult Francophone learners of English and an Anglophone control group judged the grammaticality of sets of sentences, one of which presented -self constructions that were grammatical as reflexives, as emphatics, as both, or as neither. The original purpose of this combination was to study the relation between objective ambiguity and grammaticality judgments. The results suggested not that syntactic ambiguity led to incorrect grammaticality judgments, but that garden-path (or "hard-to-get") readings of constructions which globally are asymmetrically ambiguous are associated with incorrect judgments of ungrammaticality. That is, the only reading on which a given sub-type of construction is grammatical can be unknown to leamers and even undetected by native speakers.
\end{abstract}

\section{Introduction}

The history of the study of metalinguistic awareness is largely a history of grammaticality judgments. The grammaticality-judgment literature is, after all, the main link from psycholinguistics to descriptive and, especially, theoretical linguistics. As is well known, linguistic work relies on judgments as to possible constructions and analyses which would seldom occur in normal production. Many linguists and psycholinguists have recognized that theoretical linguistics, in particular, has for years been largely interested in the status of construction types which are, in general, too close to the outer limits of the grammar to be easily found, in all their theoretically crucial variants, in any kind of natural corpora (Bever 1970, Birdsong 1989, Botha 1973, Labov 1972, Levelt 1974).

" These studies were made possible by a grant from the Social Sciences and Humanities Research Council of Canada. Our thanks to Michel Lamoureux of the Service de consultation statistique-informatique, Université de Montréal, for statistical studies referred to here. 
Here we shall be interested in a sub-topic within this problem which has received little direct attention in the literature: the relation between grammaticality status (real or perceived), on the one hand, and ambiguity (real or perceived), and more generally, the reading(s) of sentences, on the other. Our interest in this topic has led us to do a series of studies on the grammaticality judgments assigned to ambiguous sentences, on the judgments associated with readings expressed by the judge, and on the nature of the set of readings for a given sentence that are formulated by the speaker-judge.

The studies which we will report on here were, at the outset, inspired by that part of the psycholinguistic literature (Birdsong 1989, Chaudron 1983, Coppieters 1987) which is concerned with the linguistic abilities of second language learners, in comparison with those of native speakers. Before presenting these studies, therefore, we will try to indicate the relevance of the study of the human processing of ambiguity and ungrammaticality to our understanding of the linguistic abilities of speakers and learners.

Our interest, then, is in the connection between grammaticality and ambiguity, in the framework of the study of linguistic knowledge and abilities. The body of literature within psycholinguistics which comes closest to dealing with this topic directly is that on the processing of "garden-path" sentences: sentences whose parsing is generally (cf. Rayner and Sereno 1994) marked by backtracking (or "regression") of eye movements in reading studies, because of a "local" ambiguity characterized by a bias in favour of a parse which turns out to be ungrammatical. The most famous example, reappearing in many articles on this topic, is

\section{(1) The horse raced past the barn fell (Bever 1970)}

This sentence illustrates the garden-path phenomenon in English which is most commonly used in sentence-processing experiments (Fodor and Inoue 1994, Pritchett 1988). The parse preferred at the outset (out of context; cf. Trueswell and Tanenhaus 1991) is the one which turns out to be ungrammatical: raced is analyzed as a (finite) past-tensed verb form. The correct parse, usually obtained by reanalysis, has to postulate a reduced relative clause in which raced is the past participle of a past-tensed passive verb form:

\section{(2) The horse (which was) raced past the barn fell}

In this classic type, it appears that the incorrect parse is temporarily preferred because it does not involve embedding, not to mention the related fact that the frequency of subject NP + finite V constructions is greater than that of subject $\mathrm{NP}+$ past participle sequences. The other English garden-path phenomenon commonly used in experiments (Fodor and Inoue 1994, Pritchett 1988) involves 
the (local) ambiguity between matrix objects and subjects of elliptical that complement clauses:

\section{(3) I knew the man lied to the girl}

The temporary incorrect parse is motivated by the subcategorization of know in English, allowing either an NP or a sentential object.

More generally, the sentence-processing literature suggests that the need for reparsing in "garden-path" sentences, which manifest "problematic" local ambiguity (Pritchett 1988:575) has been, at least in some types of studies (Clark and Haviland 1974, Marks 1967, Van Kleeck 1982, Warner and Glass 1987), associated with judgments of ungrammaticality. This is one of the reasons why linguists and non-linguists often disagree on the grammaticality of sentences. The research on garden-path sentences has continued to be of interest in the study of the relation between (real or perceived) ungrammaticality and (real or perceived) ambiguity. Garden paths can be said to be subjectively and temporarily ungrammatical in that the first parse fails, and a second parse must be undertaken to arrive at an analysis that can be judged grammatical. Garden paths can also be said to be subjectively and temporarily ambiguous, in that at least a partial analysis other than the ultimate one is momentarily entertained, before reparsing, characterized by "regression" and/or fixation, and thus longer reading times (Rayner and Sereno 1994:284). Our search for the relation between ambiguity and judgments of ungrammaticality will lead us back to garden-path sentences below.

Our own initial question was whether the process of judging grammaticality is affected by syntactic ambiguity. We assumed that to decide if a sentence is grammatical or not, we must parse it. (At least) until we complete the parse, the sentence is subjectively ambiguous. That is, we have not (yet) delimited its possible reading(s). So attempting to parse, and in so doing potentially obtaining more than one parse, is prerequisite to judging the sentence's grammaticality. Though we began with this assumption, our research evolved toward making analyses explicit and separating them from grammmaticality judgments. The participation in our studies of advanced learners of L2 English and of translation students made this possible.

\section{The Pilot Study: Grammaticality Judgments Alone}

Our first study on the relation between grammaticality judgments and ambiguity involved judging the grammaticality of sentences, a few of which were syntactically ambiguous. The four sentence sets, three of which contained six variants of a sentence, and one of which contained four variants (22 altogether), were originally part of a larger study (Connors and Dancette 1990, 1991) involving questions on the comprehension of a short text. Each set of sentence variants 
was similar to, but not identical with, a sentence in the text. Of the 66 students in the grammaticality judgment study, 35 translation students participated in the larger study which included these judgments, while the remaining 31 students, Francophones in an advanced intermediate ESL course, performed only the grammaticality-judgment part of the larger test. All the students provided their age, mother tongue, principal language of education, number of years of university study completed, and made a self-evaluation as to the relative difficulty they had in reading texts in English, on a scale of one to eight. Though some of these variables showed interesting relations with linguistic performance, we have dealt with them elsewhere (Connors and Dancette 1990, 1991; Connors 1992), and will not be concerned with them here. All directions were in French, since even the small group of Anglophone control subjects were obliged by the nature of their programme to know French. Table 1 lists the sub-groups of students who responded to the grammaticality judgment test:

Table 1: Student Grammaticality Judges

Anglophones doing an M.A. in French $\rightarrow$ English translation 11

Francophones beginning a B.A. in English $\rightarrow$ French translation 24

Francophones in an advanced intermediate ESL course

Before each of the four sets of sentences appeared the same question: "Indépendamment de leur sens, les phrases suivantes sont-elles grammaticales?" 'Independently of their meaning, are the following sentences grammatical?' To the right of each sentence was the choice: OUI_NON_. Here are the sentences, each of whose grammaticality was judged in this way:

(4a) Peter has shown himself to be a fool

(4b) Peter has made himself to be a fool

(4c) Peter has proven himself to be a fool

(4d) Peter has shown himself that he is a fool

(4e) Peter has made himself that he is a fool

(4f) Peter has proven himself that he is a fool

(5a) There might be Peter a candidate for the job

(5b) Peter might be a candidate for the job

(5c) It might be Peter a candidate for the job

(5d) A candidate might be Peter for the job

(5e) Peter for the job might be a candidate

(5f) A candidate for the job might be Peter

(6a) If John has appealed to the voters, he might be elected

(6b) If John had appealed to the voters, he might have been elected

(6c) If John has appealed to the voters, he might have been elected

(6d) If John appeals to the voters, he might have been elected 
(7a) The Party made the candidate to run

(7b) The Party got the candidate to run

(7c) The Party had the candidate to run

(7d) The Party made the candidate run

(7e) The Party got the candidate run

(7f) The Party had the candidate run

We see that each of the four sentence sets represents a paradigm: (4) reflexive constructions followed by infinitival or sentential complements; (5) conditional might combined with word-order variation; (6) conditional and irrealis might in matrix clauses, accompanied by embedded if clauses illustrating sequence-oftense problems; and finally (7) causative auxiliaries followed by a lexical verb, with or without an intervening to. Only three of the sentences in this pilot study were both syntactically ambiguous and fully grammatical. We will repeat them here:

(4c) Peter has proven himself to be a fool

(4d) Peter has shown himself that he is a fool

(7f) The Party had the candidate run

In (4c) and (4d), the ambiguity is between reflexive and emphatic -self, while in (7f), it is between candidate as the subject of run and as the direct object of run. This last reading presupposes the grammaticality of to run a candidate (see below). Because such judgments are arguably litigious, we decided that the "correct" judgments would be those of the native Anglophone linguist-corrector, who was not involved in the conception of the study or our hypotheses.

\section{Results of the Pilot Study}

Table 2 gives the means and the standard deviations, for the super- and sub-sets of respondents, in the grammaticality test as a whole and for each of the three ambiguous sentences individually:

Table 2: Correct grammaticality judgments on the whole test and on the ambiguous grammatical sentences

\begin{tabular}{|c|c|c|c|c|c|}
\hline Groups & $\mathbf{N}$ & 22 sentences & Sent. $4 c$ & Sent. 4d & Sent. $7 f$ \\
\hline & & $\mathrm{X} \quad \mathrm{s}$ & $\mathrm{X} \quad \mathrm{s}$ & $\mathrm{X} \quad \mathrm{s}$ & $\mathrm{X} s$ \\
\hline All & 66 & 16.0612 .625 & .561 .5 & .758 .432 & .485 .504 \\
\hline Anglophone & 11 & 18.8182 .089 & $.818 \quad .405$ & .636 .505 & .636 .505 \\
\hline All Franco & 55 & 15.5092 .372 & .509 .505 & .782 .417 & .455 .503 \\
\hline Franc Trans & 24 & $16.708 \quad 2.074$ & $.625 \quad .495$ & .875 .338 & .625 .495 \\
\hline Franco ESL & 31 & $14.581 \quad 2.187$ & .419 .502 & .71 .461 & .323 .475 \\
\hline
\end{tabular}


On the basis of Table 2, it would be unjustified to pronounce on the relative difficulty of judging the grammaticality of the ambiguous sentences, compared to the sentences in general Sentence (7f) stands out as more difficult than the test as a whole, but also as more difficult than (4c), and much more difficult than (4d). In other words, the relative correctness of the grammaticality judgments on the three ambiguous sentences, while lower on the average than for the test as a whole, is not uniform: the judgments on (4d) were slightly better than those for the test as a whole, those on (4c) worse, and those on (7f) much worse. Moreover, the standard deviations for these three sentences, though appearing high, were matched by those for a number of the other (unambiguous) sentences.

Faced with this failure to demonstrate that the ambiguous sentences were more difficult or treated more heterogeneously than the sentences as a whole, we decided to examine the results for what we shall call the "litigious" sentences in the test, i.e., those for which the judgments of the Anglophone control group failed to correspond to that of the Anglophone linguist-corrector, or to that of the author of the grammaticality test (the present writer). Given the broad use of the term "garden path" in much of the recent sentence-processing literature, the judgments of many of the respondents (especially native speakers) would qualify them as garden-path sentences, in that their only grammatical parse appears to have been hard to detect, or not "preferred". These sentences were:

(4f) Peter has proven himself that he is a fool

(7c) The Party had the candidate to run

In the case of (4f), all the Anglophones, including the corrector (but not the test author) rejected the sentence. Three fourths of the Francophone Translation students and about two thirds of the Francophone ESL students accepted it, however, as we see in Table 3:

Table 3: Correct Grammaticality Judgments for "Litigious" Sentences

\begin{tabular}{lllcccc}
\hline Groups & $\mathbf{N}$ & \multicolumn{2}{c}{ Sentences $\mathbf{4 f}$} & \multicolumn{2}{c}{ Sentence 7c } \\
& & \multicolumn{1}{c}{$\mathbf{X}$} & $\mathrm{s}$ & $\mathrm{X}$ & $\mathrm{s}$ \\
All & 66 & .409 & .495 & .348 & .48 \\
Anglophones & 11 & 1 & 0 & .091 & .302 \\
All Francophones & 55 & .291 & .458 & .4 & .494 \\
Franco Trans & 24 & .25 & .442 & .292 & .464 \\
Franco ESL & 31 & .323 & .475 & .484 & .508 \\
\hline
\end{tabular}

In the case of (7c), the Anglophone corrector, after hesitating, decided that it was grammatical. Only one of the 11-member Anglophone control group and 
seven of the 24 Francophone Translation students thought likewise. Almost all of the means in Table 3, therefore, are very low.

We see, then, that the grammatically "litigious" sentences are characterized by even lower means than are the ambiguous grammatical sentences, relatively much lower than for the test as a whole, and performance on them was just about as heterogeneous as on the ambiguous sentences. We have no solid basis, therefore, for grouping the ambiguous sentences together, with respect to their fate in the grammaticality judgment test, and, in particular, no grounds for saying that they are uniformly more difficult, as objects of grammaticality judgments, than sentences in general.

What did emerge from this pilot study, however, is that in simply presenting sentences for grammaticality judgment, we do not know what syntactic analysis the respondent entertains in accepting or rejecting it. Divergence among respondents, especially native speakers, must correspond to divergent analyses where dialect differences are not a plausible explanation. Consider the "litigious" (4f) once again:

\section{(4f) Peter has proven himself that he is a fool}

For whatever reason (probably related to the inclusion of [4f] in a set of similar sentences), we saw that the Anglophone corrector and control group judged this sentence ungrammatical. This seems to mean that their parse of (4f) failed to analyze himself as an emphatic, for this is the only reading on which the sentence is grammatical. Alternatively, the emphatic -self form may have been read but be unacceptable to these judges between the lexical verb and a sentential complement. The case of (7c) is less mysterious, if we assume that the majority of these speakers' and learners' grammars do not permit candidate as an object (patient) of run, on the basis of (lexical) selection restrictions.

Nevertheless, such explanations are speculative-unjustified on the basis of grammaticality judgments alone. This is why, in the next stage of our research, we decided to try to elicit the syntactic analysis on whose basis the respondents made the grammaticality judgment. The apparently problematic alternation (and potential ambiguity) between reflexive and emphatic -self was to be the focus of this new phase of the investigation.

\section{The Study on -self Constructions}

The Questionnaire

We constructed a questionnaire whose central feature was the presentation of the following 15 minimal sentence pairs, without the reflexive pronoun and then with it, in that order. The position of the -self form was crucial, not only to al- 
lowing for real or perceived syntactic ambiguity, but also to setting up grammatically problematic contexts for the emphatic:

(8a) Mary sat (herself) down

(8b) John learned (himself) to play the piano

(8c) John showed (himself) to be successful

(8d) John absented (himself) from class

(8e) John remembered (himself) how the accident happened

(8f) John reminded (himself) how the accident happened

(8g) Mary weakened (herself)

(8h) Mary dressed (herself)

(8i) This jacket washes (itself) well

(8j) I sang (myself) a song

(8k) Paul believes (himself) to be intelligent

(81) Paul pretends (himself) to be intelligent

(8m) I imagined (myself) on vacation

(8n) I am applying (myself) to the task

(80) I am applying (myself) for the job

\section{The Respondents}

The questionnaire was submitted to 54 students altogether, in one or the other of two undergraduate French $\leftrightarrow$ English translation programmes in two Canadian universities. They were in one or the other of two corresponding courses, each in one of the matched universities, devoted to problems in translating from French to English. Responses to a preliminary questionnaire indicated that they fell clearly into three groups: 25 Francophones (French mother tongue and main language of schooling); 17 Anglophones (English mother tongue and main language of schooling); and 12 "Mixed" speakers (i.e. French $\leftrightarrow$ English bilinguals and students having other mother tongues). Tables 4 and 5 below will refer to these respondent groups.

\section{The Procedure}

Before being asked to do anything with the sentences in (8) above, the students read a four-page introduction to the study along with the examiner, who in fact read it aloud to each of the two classes. This introduction came in two very closely corresponding versions: in French for the class which was almost entirely Francophone and in English for the other, mainly Anglophone class. It presented our conception of a layman's typology of the reflexive pronoun's use in English. First, this pronoun can be "necessary" because the verb is obligatorily reflexive (e.g., John availed himself..., and not *John availed...), or because the (obligatory) complement refers to the same person as the subject (I saw myself and not *I saw me ). It can be "superfluous": the verb can simply not 
allow a reflexive in the given context: A crowd gathered *itself. It can also be "optional", a category which includes what have been called "semi-reflexives" (Quirk et al. 1985): I shaved (myself) this morning. Finally (and crucially), it can be emphatic, having the same role as French lui-même. Here, we gave the example: John was himself aware of the problem.

The introduction then presented in some detail the notions of syntactic ambiguity, on the one hand, and grammaticality, on the other. The former concept was explicated by working through (and noting explicitly) the reflexive/emphatic ambiguity of: John showed himself that he was a coward. The notions of "paraphrase" and "translation" were then presented briefly. The directions then asked the respondent to decide, for each of the 30 sentences (each of the two forms of each sentence in [8] above), first, whether it was syntactically ambiguous. If not, one interpretation of the sentence was to be expressed in the form of one French translation or (English) paraphrase. If so, the respondent was to give a translation or paraphrase corresponding to each of the interpretations, limiting himself to two. Finally, he was to decide, for each interpretation, whether the original English sentence (each of those in [8]) was a grammatical way to express that meaning. As a last step, the introduction worked through the following example, which illustrates the format in which all 30 sentences were presented and were to be dealt with:

\section{(9) John proved himself that he was successful}

Interpretations:

(i) John lui-même a prouvé qu'il avait réussi

(ii) John s'est montré qu'il avait réussi

yes

no

yes

no

The directions went on to explain that we had been able to decipher two interpretations for (9). For the first, the original English sentence was grammatical. For the second, the original sentence was ungrammatical, since one would have to have said "John proved to himself...". This was why we had chosen no at the end. The respondents then devoted approximately 45 minutes to answering the questionnaire, treating each sentence in (8) on the model of (9).

\section{The Hypotheses}

We hypothesized that even such advanced learners of English as our nonAnglophone respondents would not show the same knowledge of the possible complement structure of the verbs in (8) as would Anglophones. There would be differences among Anglophones and learners, then, in the judgments on the reflexive and non-reflexive interpretations proposed, insofar as these judgments 
1) would have to take into account the divergences in complement structure between the English verb in the original sentence and its French counterpart, and 2) would reveal, among the learners, gaps in knowledge of those English verbs' complement structures. We also hypothesized that there would be a bias in favour of reflexive, as opposed to emphatic, interpretations for the respondents generally. The emphatic readings would be "hard to get" because the emphatic reflexive form does not represent an argument. This "anti-emphatic" bias would surface not only in the numbers of reflexive vs. emphatic interpretations proposed, but also in the relative frequency with which respondents would reject their own interpretations because the task encouraged them to fabricate an interpretation which they could then reject on the grounds that the original English sentence was not a grammatical way to express that meaning.

\section{Results of the -self construction study}

What kinds of linguistic analyses would enable us to test these hypotheses? To evaluate the extent to which each group of informants (the Francophones, the Anglophones, and the Mixed group) showed knowledge of the argument structure of the verbs in the test sentences, we judged the correctness of the grammaticality judgments that each subject associated with his own interpretations. Was he right or wrong in judging the fit between each original English sentence and the interpretation he had proposed for it? In the case of the seven totally ungrammatical sentences (in most instances the variant of the sentence pair which lacked the -self form), the respondent should simply have rejected his interpretation(s) of the sentence, since there was no interpretation for which the original English sentence was a grammatical expression. In the case of the 23 grammatical sentences, the judgment on each interpretation was evaluated according to whether the respondent was right or wrong in saying that the original English sentence could or could not have the interpretation which he had proposed. In fact, we judged whether they were right or wrong in accepting or rejecting their interpretations insofar as they did or did not contain a reflexive or an emphatic. Other aspects of the interpretations were ignored.

Table 4 summarizes the performance of the three groups of respondents with respect to the correctness of their grammaticality judgments on their interpretations, i.e., their judgments as to the fit between their interpretations and the original English sentences. It shows that the only significant difference here is that between the Francophones and the Anglophones, in favour of the latter, in accord with our first hypothesis. Table 5 shows that the "Mixed" group of respondents had a significantly greater tendency than the Anglophones to propose and wrongly accept reflexive interpretations for sentences which were only grammatical on the emphatic reading. This was one of the manifestations of an "anti-emphatic bias": 
Table 4: Correctness of grammaticality judgments on interpretations

Francophones (25) $67.44 \%$

$$
\text { Francophones } ¥ \text { Anglophones: } \quad \text { F-ratio } \quad \text { F-probability }
$$

$8.7904 \quad .0005$

Anglophones (17) $80.27 \%$

Mixed (12) $\quad 75.30 \%$

Table 5: Purely emphatic sentences: reflexive interpretations proposed and accepted

Francophones (25) $18.92 \%$

Anglophones (17) $06.27 \%$

Anglophones $¥$ Mixed: $\quad$ F-ratio $\quad$ F-probability

$4.0979 \quad .0224$

Mixed (12) $\quad 23.30 \%$

Turning from performance differences among the respondents to sentences and interpretations, we can ask whether the potentially and the purely emphatic sentences have suffered from a bias against their grammaticality, and whether emphatic interpretations of grammatical but ambiguous sentences suffered from a disproportionate tendency to be rejected. Table 6 compares the extent to which the grammatical sentences in general were totally rejected with the extent to which the emphatic grammatical sentences were totally rejected. By "total rejection" of a sentence we mean the situation in which the respondent rejects the one or both reading(s) he proposed for it. The results in Table 6 confirm the hypothesis of a bias against the emphatic. Purely and potentially emphatic sentences did suffer from a special tendency to be "rejected", in the sense adopted for our study, though the last three lines of Table 6 show that this bias was far from evenly distributed among emphatic sentences, for reasons which we cannot explain:

Table 6: [+grammatical] sentences and their total rejection: Judged ungrammatical on reading(s) proposed
(A)
All purely emphatic sentences (grammatical iff emphatic)
4
(B)
All grammatical sentences
23
(C) $\quad \mathrm{A} / \mathrm{B}$
(D) Total rejections of purely emphatic sentences
$17,4 \%$
(E) Total rejections of grammatical sentences
(F) D/E
(G) Sentences [+grammatical] on both readings ( $8 \mathrm{~g} \& 8 \mathrm{~h}$ )
184
(H) Total rejections of $8 \mathrm{~g}$
(I) Total rejections of $8 \mathrm{~h}$
2
14
Total rejections of $8 \mathrm{~g} \& 8 \mathrm{~h}$
1
15

If we now focus on interpretations, we can compare the judgments on the emphatic interpretations of the grammatical sentences which were ambiguous be- 
tween the reflexive and emphatic readings ([8g] and [8h]) to judgments on interpretations of grammatical sentences in general Table 7 presents this comparison. We see that for the grammatical but ambiguous sentences, the emphatic interpretations, which, contrary to the expectation implicit in our hypothesis of an "anti-emphatic" bias, were in the majority, nonetheless had a much lower rate of acceptance than did interpretations of grammatical sentences generally:

Table 7: 8g \& 8h: [+emphatic] interpretations and judgments of interpretations
(A) All interpretations of $8 \mathrm{~g} \& 8 \mathrm{~h}$
167
(B) [-emphatic] interpretations of $8 \mathrm{~g} \& 8 \mathrm{~h}$
74
(C) [+emphatic] interpretations of $8 \mathrm{~g} \& 8 \mathrm{~h}$
93
(D) [+emphatic] interpretations of $8 \mathrm{~g} \& 8 \mathrm{~h}$ judged gram
53
(E) All interpretations of grammatical sentences
1690
(F) All interpretations of grammatical sentences judged gram.
1125
(G) $\mathrm{D} / \mathrm{C}$ ( $\%$ of +emph interpretations of $8 \mathrm{~g} \& 8 \mathrm{~h}$ judged gram.)
(H) $\mathrm{F} / \mathrm{E}(\%$ of interpretations of gram. sentences judged gram.)
(I) Interpretations of $8 \mathrm{~g}$ judged ungrammatical
(J) Interpretations of $8 \mathrm{~h}$ judged ungrammatical
22

\section{Conclusion to the -self construction study}

The results of this study suggest that native speakers, as expected, show a surer grasp of the contexts where the reflexive, the emphatic, both, or neither construction can occur. Also as expected, the respondents generally showed a systematic bias against emphatic -self constructions grammaticality judgments associated with interpretations. The disproportionate rejection of the "purely emphatic" sentences may be explained by assimilating them to "garden paths": the only interpretatioin on which they are grammatical is "hard to get". The tendency of our respondents to reject their own emphatic interpretations, however, indicated a more general phenomenon of rejecting the disfavoured reading of asymmatrically ambiguous constructions. In addition, however, the study indicated that speakers and learners can be acutely sensitive to possible emphatic readings of reflexive pronoun constructions. Of further and more general interest is the systematic ability and willingness of our respondents to envisage potential sentence interpretations independently of the grammaticality of the sentence on each interpretation. In other words, a possible meaning of a sentence can be comtemplated independently of whether the sentence is a grammatical way of expressing that meaning. Interpretability, including subjective ambiguity, is thus in principle independent of subjective grammaticality. The fact that the respondents were students of translation was surely an important factor in eliciting such results. It was, nonetheless, remarkable that the linguistic awareness of both the native speakers and the learners could adapt ,without extensive metalinguistic training, to the task of distinguishing and yet relating interpretation, including ambiguous interpretation, to the task of judging grammaticality. 


\title{
The French pronominal-verbal construction study
}

\author{
Introduction:
}

The respondents, procedure, and questionnaire

Our last study in this series examined the interpretations assigned to French pronominal-verbal constructions. The design of this study corresponded in important respects to that on interpretations of -self constructions. The 38 respondents were again Francophone and Non-Francophone students in two corresponding university programmes leading to a B.A. in English $\rightarrow$ French or French $\rightarrow$ English translation. Also as in that study, their help was sollicited in matched second-year courses devoted to problems in translation from French to English. For the Francophone half (19) of the respondents, the $\mathrm{Ll}$ and the principal language of schooling was French. The 19 Non-Francophones had English as their mother tongue and/or as their principal language of schooling, usually both.

These new student-respondents were again given a written explanation which was also read aloud by the examiner (in French or English, depending on the main language of the class). It started with four possible interpretations of the French pronominal-verbal construction: the reflexive, reciprocal, intrinsic, and passive readings. Each of these was explained, in the terms of traditional grammar, and illustrated with simple examples. Then there was an explanation of syntactic ambiguity, first with an illustration having nothing to do with the pronominal-verbal construction. Then, three syntactically ambiguous sentences containing this construction were examined, with paraphrases bringing out the two or three readings in each case. Each interpretation presented was explicitly labelled: reflexive, reciprocal, intrinsic, or passive. Then, attention was called to the distinction between a "translation" and a "paraphrase", for, as in the previous study, these new groups of respondents were about to be asked to express interpretations of sentences in one or the other of these two ways. The last page of explanation-instructions was devoted to the task. Repeating a short, simple example of a three-ways-ambiguous sentence containing the pronominal-verbal construction, we worked through the task with it: Beneath each sentence would be four pairs of lines providing space for each of the four types of potential interpretations. To the right of each pair of lines was the label for an interpretation type: reflexive, reciprocal, intrinsic, and passive, always listed in that order. The respondent was asked, for each sentence, first to circle the name for each type of interpretation the sentence had, and then to write a translation or a paraphrase corresponding to each of these interpretations.

Here are the 20 French sentences which the 38 respondents treated in this way. We give their possible types of interpretations here, but of course did not do so on the questionnaire presented to the respondents: 
(10) Ce livre se vend bien (passive)

(11) Les passants s'aperçoivent dans la glace (reflexive, reciprocal, passive)

(12) Les enfants se surveillent bien de la fenêtre (reciprocal, passive)

(13) Les grands savants s'admirent (reflexive, reciprocal, passive)

(14) Jean et Paul se parlent (reflexive, reciprocal)

(15) Les lumières s'allument à six heures (reflexive, passive)

(16) Mathieu se sert du café (reflexive. intrinsic)

(17) Jean se déteste (reflexive)

(18) Alexandre et Denis se sont sauvés (reflexive, reciprocal, intrinsic)

(19) Ils s'aperçoivent de leurs propres erreurs (intrinsic)

(20) Pierre et Simon s'appliquent à leur trovail (intrinsic)

(21) Mathieu se sert du marteau (intrinsic)

(22) Ces types de personnes se rencontrent dans ce bar (reciprocal, passive)

(23) Pauline et Yves s'entendent bien (reflexive, reciprocal, intrinsic, passive)

(24) Les coupables se pendent dans la prison (reflexive, reciprocal, passive)

(25) Marie s'évade du couvent (intrinsic)

(26) Les enfants se comportent bien à l'école (intrinsic)

(27) Pierre et Jean s'écrivent de nombreuses notes (reflexive, reciprocal)

(28) Simon et Anne se sont rencontrés dans ce bar (reciprocal)

(29) Paul et Anne se marient (reflexive, reciprocal)

The instructions assured the respondents that each of the 20 questionnaire sentences was grammatical for at least one interpretation, and that each sentence was not necessarily ambiguous. We see, in (10)-(29), of course, that 12 of the 20 sentences were, in reality, syntactically ambiguous, seven of them two-ways, four of them three-ways, and one of them four-ways. This widespread ambiguity was reflected in the hundreds of interpretations furnished by our 38 respondents.

\section{Results of the pronominal-verbal construction study}

The bias in favour of dominant readings, where the reflexive pronoun represents an argument of the verb, showed up in this study as it had in the analogous study of -self constructions. The results on which we will concentrate here, however, are those which demonstrate the relative ability of advanced L2 learners to express correct interpretations of ambiguous sentences through paraphrase and translation. We shall also see that, in a study which called attention to ambiguity, the relatively numerous ambiguous sentences elicited relatively few incorrect interpretations, and several hundred correct ones. Table 8 shows that, for the exacting task of both supplying (only) the correct reading(s) for each sentence and identifying the linguistic nature of each reading, the means 
were modest, and the Non-Francophones performed significantly better than the Francophones. Table 9 shows that the same was true when we considered the task, for each sentence, to have been correctly performed only if the exactly right combination of readings was supplied:

Table 8: Identifying and supplying readings of pronominal-verbal constructions: performance on 4 theoretically possible reading types for 20 sentences

\begin{tabular}{lccccc}
\hline Respondent Group & N & Mean/80 & Standard Deviation & $t$ & Probability \\
Francophones & 19 & 52.5263 & 8.106 & & \\
Non-Francophones & 19 & 59.1053 & 8.034 & -2.51 & .017 \\
\hline
\end{tabular}

Table 9: Supplying the required combinations of readings for 20 sentences

\begin{tabular}{lccccc}
\hline Respondent Group & N & Mean/20 & Standard Deviation & t & Probability \\
Francophones & 19 & 5.1579 & 3.304 & & \\
Non-Francophones & 19 & 8.1053 & 3.695 & -2.59 & .014
\end{tabular}

The superiority of the Non-Francophones in this set of tasks can be accounted for: Table 10 shows the number of translations and the number of paraphrases proposed by the 19 Francophone and the 19 non-Francophone respondents:

Table 10: Translations and paraphrases proposed by francophones and non-francophones for 20 sentences

$\begin{array}{lccc}\text { Respondent Group } & \text { Translations } & \text { Paraphrases } & \text { All Interpretation } \\ \text { Francophones } & 131(20.5 \%) & 509(79.5 \%) & 640(100 \%) \\ \text { Non-Francophones } & 576(81.8 \%) & 128(18.2 \%) & 704(100 \%) \\ \text { Totals: } & 707 & 637 & 1344 \\ \text { Proposed by F } & 18,5 \% & 79,9 \% & 100 \% \\ \text { Proposed by non-F } & 81,5 \% & 20,1 \% & 100 \%\end{array}$

Reading the percentages from left to right, we see that the Francophones tended strongly to propose paraphrases for the 20 sentences, and the NonFrancophones tended strongly to propose English translations for them. The last two lines of Table 10 show the proportion of the total number of translations and paraphrases which were proposed by the respondents in each lnaguage group. We see that the Francophones proposed the greater proportion of the paraphrases, and the Non-Francophones the greater proportion of the translations. In fact, attempting to translate the 20 sentences was, in general, the better strategy, since English has distinct morphosyntactic constructions correspond- 
ing to the reflexive, reciprocal, passive, and intrinsic (= active intransitive) readings of the French pronominal-verbal construction.

Table 11, on the other hand, shows, for the 38 respondents as a whole, their relatively great success in interpreting ambiguous, as opposed to unambiguous sentences. The "correct" and "incorrect" interpretations are of course those proposed of which the bilingual corrector was able to judge the correctness:

Table 11: Correct and incorrect interpretations by 38 respondents for 12 ambiguous and 8 unambiguous sentences

Sentences

$\begin{array}{lc} & \text { Correct } \\ & \\ \text { Ambiguous (12) } & 805(73.6 \%) \\ \text { Unambiguous (8) } & 289(26.4 \%) \\ \text { All Interpretations whose } & \\ \text { Correctness Could Be Judged } & 1094(100 \%)\end{array}$

Interpretations

Incorrect

$124(51.2 \%)$

$118(48.8 \%)$

$242(100 \%)$

Reading the percentages from top to bottom, we see in Table 11 that the ambiguous sentences elicited the vast majority of the correct interpretations, and only slightly more than half of the incorrect ones. It is mainly this last percentage whic is surprising, since the task of interpreting ambiguous sentences did of course elicit many more attempts than did that of interpreting unambiguous ones.

\section{General Conclusion}

The most remarkable outcome of this series of studies is the extent to which eliciting interpretations in addition to, or instead of grammaticality judgments generated data which cast light on the possible readings of ambiguous and otherwise problematic sentences. Indeed, we have seen that it is not ambiguity in itself which is problematic, but the biases elicited by the task of interpreting asymmetrically ambiguous constructions. The many hundreds of interpretations which our translation-student-respondents proposed, however, for sentences exemplifying such constructions, show that such exercises in implicit syntactic analysis can lead advanced adult L2 learners to resolve syntactic ambiguity, and show their understanding of the semantic possibilities of such constructions.

\section{REFERENCES}

Bever, T.G. 1970: The cognitive basis for linguistic structures. In: Hayes, J.R., editor, Cognition and the Development of Language. New York: Wiley, 279-362.

Birdsong, D. 1989: Metalinguistic Performance and Interlinguistic Competence. New York: Springer. 
Botha, R.P. 1973: The Justification of Linguistic Hypotheses: Study of Non-Demonstrative Inference in Transformational Grammar. The Hague: Mouton.

Chaudron, C. 1983: Research on metalinguistic judgments: A review of theory, methods and results. Language Learning 33, 343-77.

Clark, H.H. and Haviland, S.E. 1974: Psychological processes as linguistic explanation. In: Cohen, D., ed., Explaining Linguistic Phenomena. Washington, D.C.: Hemisphere, 91-124.

Connors, K. 1992: Judging the grammaticality of ambiguous sentences in a second language. Paper presented at the XVth International Congress of Linguists.

Connors, K. and Dancette, J. 1990: Text comprehension and linguistic awareness in advanced learners of English. Paper presented at NWAVE XLX.

- 1991: Conprehension de textes et conscience linguistique chez les apprenants d'une langue seconde. Paper presented at the Annual Meeting of the Canadian Association of Applied Linguistics.

Coppieters, R. 1987: Competence differences between native and near-native speakers. Language $63,544-73$.

Fodor, J.D. and Inoue, A. 1994: The diagnosis and cure of garden paths. Journal of Psycholinguistic Research 23, 407-34.

Labov, W. 1972: Sociolinguistic Patterns. Philadelphia: University of Pennsylvania Press.

Levelt, W.J.M. 1974: Formal Grammars in Linguistics and Psycholinguistics. 3 volumes. The Hague: Mouton.

Marks, L.E. 1967: Judgments of grammaticalness of some English sentences and semi-sentences. American Journal of Psychology 80, 196-204.

Pritchett, B.L. 1988: Garden path phenomena and the grammatical basis of language processing. Language 64, 539-76.

Quirk, R., Greenbaum, S., Svartvik, J. and Leech, G. 1985: Comprehensive Grammar of the English Language. New York: Longman.

Rayner, K. and Sereno, S.C. 1994: Regresive eye movements and sentence parsing: on the use of regression-contingent analyses. Memory and Cognition 22, 281-85.

Trueswell, J.C. and Tanenhaus, M.K. 1991: Tense, temporal context and syntactic ambiguity resolution. Language and Cognitive Processes 6, 303-38.

Van Kleeck, A. 1982: The emergence of linguistic awareness: A cognitive framework. MerrillPalmer Quarterly 28, 237-65.

Warner, J. and Glass, A.L. 1987: Context and distance-to-disambiguation effects in ambiguity resolution: Evidence from grammaticality judgments of garden path sentences. Journal of Memory and Language 26, 714-38. 